\title{
BIM - AN APPLICATION IN GEOTECHNICAL ENGINEERING
}

\author{
IVAN VANÍČEK*, JAN PRUŠKA, DANIEL JIRÁSKO
}

\begin{abstract}
Czech Technical University in Prague, Faculty of Civil Engineering, Department of Geotechnics, Thákurova 7, 16629 Prague 6, Czech Republic

* corresponding author: ivan.vanicek@cvut.cz
\end{abstract}

\begin{abstract}
BIM model represents a significant step forward within the frame of the overall process of construction. This new approach goes from the assumption that up to date praxis, which is represented by different sets of $2 \mathrm{D}$ or $3 \mathrm{D}$ drawings of drawings, technical reports and calculations does not cover all problems of the above mentioned overall process of construction. Basic principles of BIM will be discussed, not only from the view of 3D models of the structure design. The utilization of the BIM model during life time structure expectancy will be stressed - from the initial phase (investigation, design) via the phase of structure execution, maintenance and ending with structure demolition at the end of life time expectancy. Specificity of the geotechnical engineering is in this entire process fundamental, as each construction is in the interaction with ground. 3D model of the ground (geotechnical model) is therefore one of the basic individual parametric elements from which BIM model consist. Ground model is time dependant as geological profile and geotechnical properties are refinement during each phase of ground investigation as well during geotechnical structure construction. Final 3D Ground model together with 3D model of geotechnical structure represents a first significant step of the overall BIM model. In the case of underground or earth structures such output can be primordial element of the BIM model with parametric elements around it. Finally some other possibilities or practical applications are mentioned.
\end{abstract}

KEYWORDs: BIM, Geotechnical engineering, ground model, model of the realized geotechnical structure, sustainable construction.

\section{INTRODUCTION}

BIM - Building Information Modelling (Management) as a tool for the process of optimizing construction activities is connected over the most recent period with a more general digitalization evident throughout all industries. The term Průmysl 4.0 (Industry 4.0) or Stavebnictví 4.0 (Building 4.0) is now standard for most elements of building engineering. As from now more attention is being devoted also in Civil Engineering and some significant Czech investors and construction companies are demanding that they receive data in the form of the BIM model in order to be able to digitalize the process of construction. However the main condition for the application of the BIM model in the wider profession is a clear understanding of BIM principles. There are many different aspects to a definitive BIM. The first one, that BIM is simply a 3D model of the engineering structure, is not correct as it does not take into account up to date instruments of information modelling concerning engineering structures and modern communication methods. The most widely used definition was specified by the American National Committee for the BIM standard: "Building Information Modelling (BIM) is a digital presentation of physical and functional characteristics of a facility. A BIM is a shared knowledge resource for information about a facility forming a reliable basis for decisions during its life-cycle, so defined as existing from earliest conception to demolition" [1].

In other words BIM can be understood as a process for optimization of the engineering structure right through conception, design, execution and operation. By this approach the 3D computer model is a fundamental part of BIM but however is enlarged by additional information on such matters as time, financial expenses, structure maintenance etc - with new so called $4 \mathrm{D}, 5 \mathrm{D}$, and generally $\mathrm{nD}$ models.

\section{The situation in the Czech REPUBLIC}

The Decree of the Government No. 82: "A Concept for the implementation of the BIM model In the Czech Republic" instigated September 252017 can be taken as the basis of BIM acceptance. The main driver is the Ministry of Industry and Trade which accredited the Czech agency for standardization (CAS) responsible for the realization of this governmental decree. Some results of CAS activities are described in 22. From this analysis some basic reflections, facts and expected developments can be mentioned.

From the reflections there can be cited "BIM is about change - respectively processes, ideas, working habits, and " the improvement of cooperation, information sharing along with an interrelationship cultivation that helps the higher effectiveness of engineering structures projects". From the actual facts, six 
working groups can be mentioned and some results are presented at www.koncepceBIM.cz. Activities of CAS are coordinated in a European framework by positive participation in CEN TC 442 - Building Information Modelling (BIM).

The advantages of the BIM are now primarily emphasized with respect to the practical application for engineering facilities of buildings, e.g. in articles 3] and 4. The authors of the second paper dealing with building of a hospital in Náchod stress the ratio of the construction to the operating charges for the expected life time expectancy of the building which they estimate to be $20: 80$. At the same time of course they are stressing the main idea: "the more quality we buy at the beginning, the less we spend later on". Naturally, this should be valid also for civil engineering structures such as transport infrastructure. When the transport engineering structure is made to be more robust, then less should be needed in the future for maintenance, reconstruction or on the restoration of services after natural hazards such as e.g. floods, rock falls; as any restraint of services can be included into additional expenses.

The third note refers to the activities of SFDI - Governmental Fund of Transport Infrastructure which is responsible for BIM implementation for transport engineering. Procedures of SFDI are very important with the respect to the above-mentioned governmental decree according to which all significant funded projects disbursed from the government budget should be contracted within the BIM regime from 2022. SDFI, currently in September 2019, approved the provisional version of the document "Directive for BIM pro structures of transport infrastructure - Data standard - for PDPS - Project documentation of structure realization (execution)". In this provisional version attention is devoted to the project documentation for structure execution, and therefore up to some extent it is outwith the main aim of the BIM - to interconnect previous steps of the project documentation, even when some parts of the DUR (documentation for planning inquiry), DSP (documentation for building permit) are mentioned in annexes 1 and 2 dedicated to road and railway structures. A "Directive" can specify rules for the collection of data for BIM in such a way that it can be used by owners, designers, contractors in all phases of design, execution and transport infrastructures maintenance.

The Data Standard is based on the open data format IFC, see ČSN EN ISO 16739 (730100) from April 2017. The IFC data format is playing the role of the Coordination model of construction, which is composed of the individual construction sets, operational sets or engineering objects. This Co-ordination model is used for the mutual coordination of the fragmental models, for the detection of collisions, in all construction display, for display of individual phases of the construction process and also for creation of cross sections. The Co-ordination model is in principle an individual set, which contains the fragmental models.

\section{BIM AND GEOTECHNICAL ENGINEERING}

Geotechnical engineering has an indispensable role in BIM , as all structures are in some interaction with ground and this interaction is provided by foundation structures - Fig. 1] The term structure is composed not only of the upper structure but also of foundation structures, including ground which is influenced by the total construction and includes a view of stresses, deformation or permeability. Fragmental models for which the geotechnical engineering is responsible should therefore consist of the Ground model, the Geotechnical design model, the Calculation model and also by a model of the real execution of the geotechnical structure with its connection to the Ground model. These fragmental models from which all others models proceed can bring a significant recognition of the role of geotechnical engineering in the whole construction process. At the same time these fragmental models can lead to a more significant utilization of the basic principles of, and demands on, geotechnical structures, which are in Europe specified in sets of Eurocodes, initially in Eurocode (EC 7) Geotechnical Design.

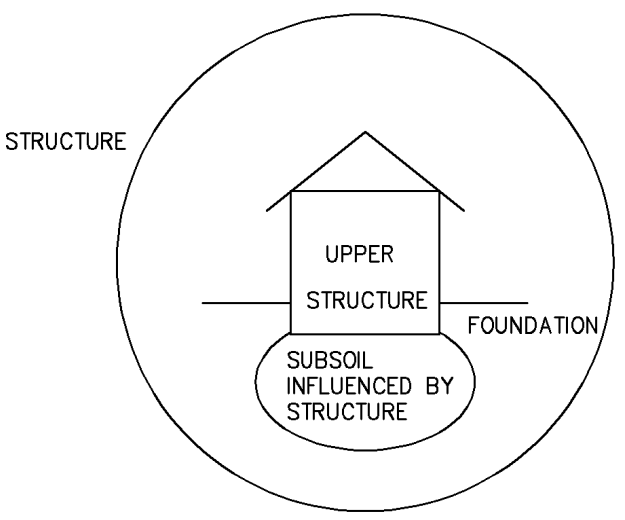

FIGURE 1. Interaction of structure and subsoil

All the above mentioned is valid for foundation structures, see Fig. 2.a., but similarly, if not more significantly, for other geotechnical structures such as earth structures (for transport, water or environmental engineering) or underground structures (tunnels, underground repositories, metro...) as these geotechnical structures can even be the main element of the solved construction, Fig. 2 b.

The significance of fragmental geotechnical models stands front rank as the main project idea in the phase of alternative solutions of the construction situation (placements) that should arise from the first phases of the Ground (geological) model. This first phase of the geotechnical investigation is denoted as desk study and uses all previous information, firstly different geological maps, then engineering geological maps, hydrogeological maps, more generally from the 


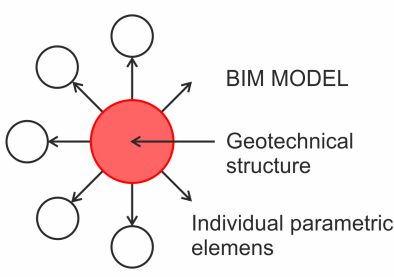

a)

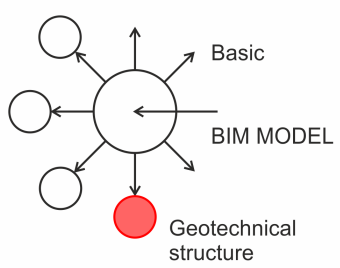

b)
Figure 2. The position of geotechnical BIM model for various geotechnical structures. Ad a) Geotechnical structure creates a basic BIM model. Ad b) GS creates an individual parametric elementaround basic BIM model.

set of so called geo-environmental maps, as this set includes also information about raw materials, about quality of underground water which should be protected etc. Their utilization is also for the EIA process - Environmental Impact Assessment - for the phase of the evaluation of different variants of the transport infrastructure lines.

The Ground model is step by step improved so as to be able to fulfil demands on the individual stages of the design and will be terminated by the model which was verified during the phase of structure execution. The final version can be used for whole life time expectancy should any new interaction start.

\subsection{Foundation STRUCTURES}

The 3D model of the ground together with the 3D model of the foundation structure can be used for verification of the basic rules which are specified in the Eurocode 7 Geotechnical Design and involve:

- To what degree the investigation methods respect the significance of the geotechnical structure and the risk with which any failure is connected - which is in the EC 7 expressed by 3 different geotechnical categories;

- Whether the depths of the investigation works are catching the maximum depths influenced by the proposed construction;

- Whether the range of the proposed and completed field and laboratory tests make possible their credible evaluation;

- What differences there are between the measured values of geotechnical parameters, and which were finally used during the design as characteristic values, and with the values obtained during structure execution. Similarly this is valid for step by step improvement of boundaries between individual lithological layers.

As the BIM model is time dependant there is the possibility to intervene at any time to correct potential shortcomings. Similarly this is valid for geotechnical structures for which limit states are very sensitive to time, as from the ULS with respect to short-term bearing capacity (stability) so on for long-term bearing capacity (stability) and then so for the SLS verification. Therefore, geotechnical structures get benefit from the monitoring plan not only during the phase of construction but also for the phase of construction of the upper structure, as well as during the period of warranty, to confirm that all demands are satisfied. The monitoring plan or plan of maintenance can create an independent fragmental model.

The BIM model is also able to control the schedule of the construction process, e.g. piles with additional information about pile execution, testing and a quality of material confirmation.

\subsection{EARTh STRUCTURES}

As the set-up of the BIM model is very significant for transport infrastructure our attention is focused on these earth structures in transport engineering. Timing specification is shown in Fig. 3 for individual parts of the Geotechnical Design Report (GDR). There are two geological models, the first one for subsoil and the second one for borrow pit, and from which material will be used for fill. Similarly tests will be carried out for these two basic materials. For embankment, the quality of subsoil is not controlled during execution, and attention is devoted to the control of deposited and compacted material from the borrow pit. In principle there should be two levels of control, for compaction and for material properties (strength, deformation, filtration parameters) as these were used during the design. However, the possibilities in the second direction are very limited.

The 3D model of subsoil together with the constructed earth structure (embankment) is shown in Fig. 4. There are also supplementary cross-references on the description of investigation points (boreholes) on measure properties, and on the final selection of characteristic values of geotechnical parameters. Similarly, as for foundation structures, the BIM model can be used for approval on whether the model of subsoil is sufficient specifically with respect to the geotechnical category into which the designed geotechnical structure is falling.

\subsection{UNDERGROUND STRUCTURES (TUNNELS)}

As the BIM model is proposed for total life time expectancy a significant role is present also for the phase of structure preparation (study). This is so especially with the respect to traffic line selection, the selection of technology for tunnel performance, a statement about material demands, and financial cost estimation. For embankment or cuts the estimation is relatively easy compared to the estimation for tunnels. The main reason is that during a tunnel execution unexpected geological and geotechnical conditions can be discovered because during the actual geotechnical investigation only a limited volume of the rock massif can be in fact be subject to this investigation. In this 


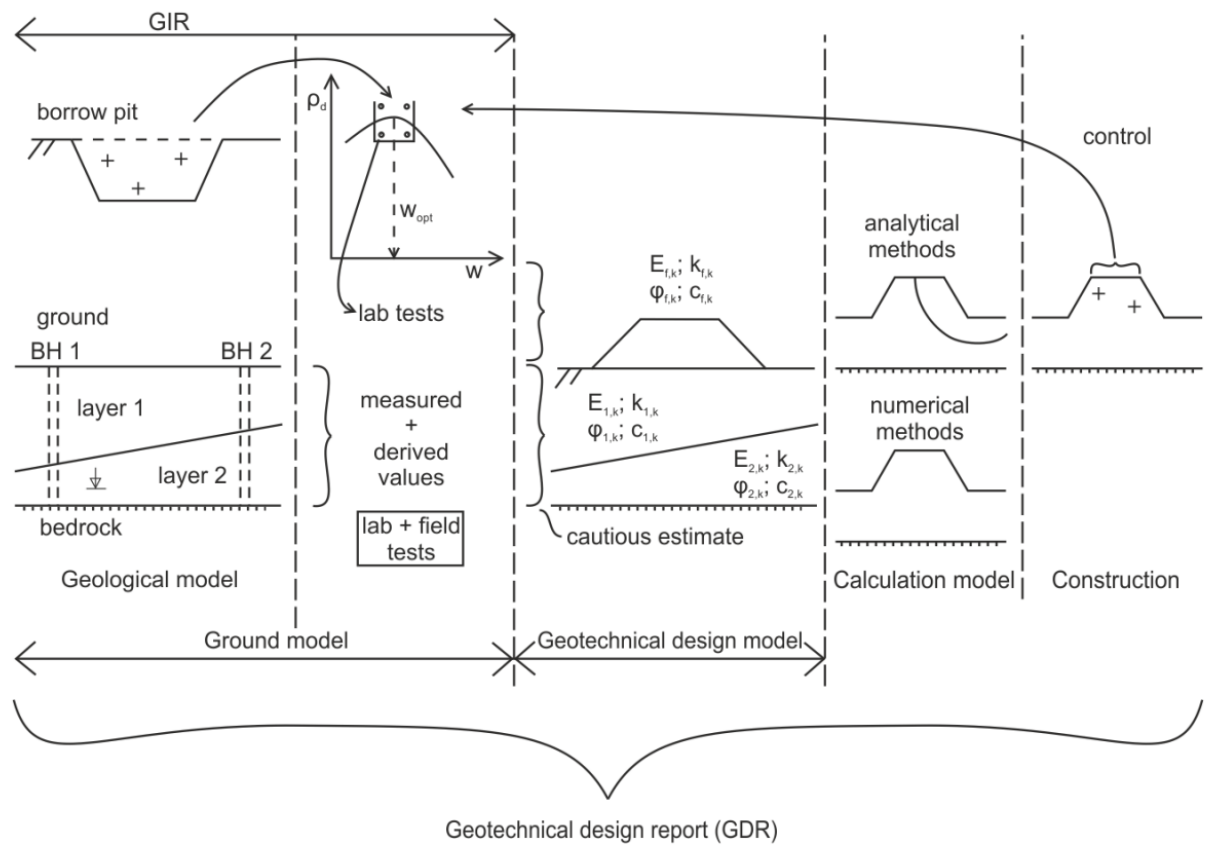

Figure 3. Geotechnical Design Report

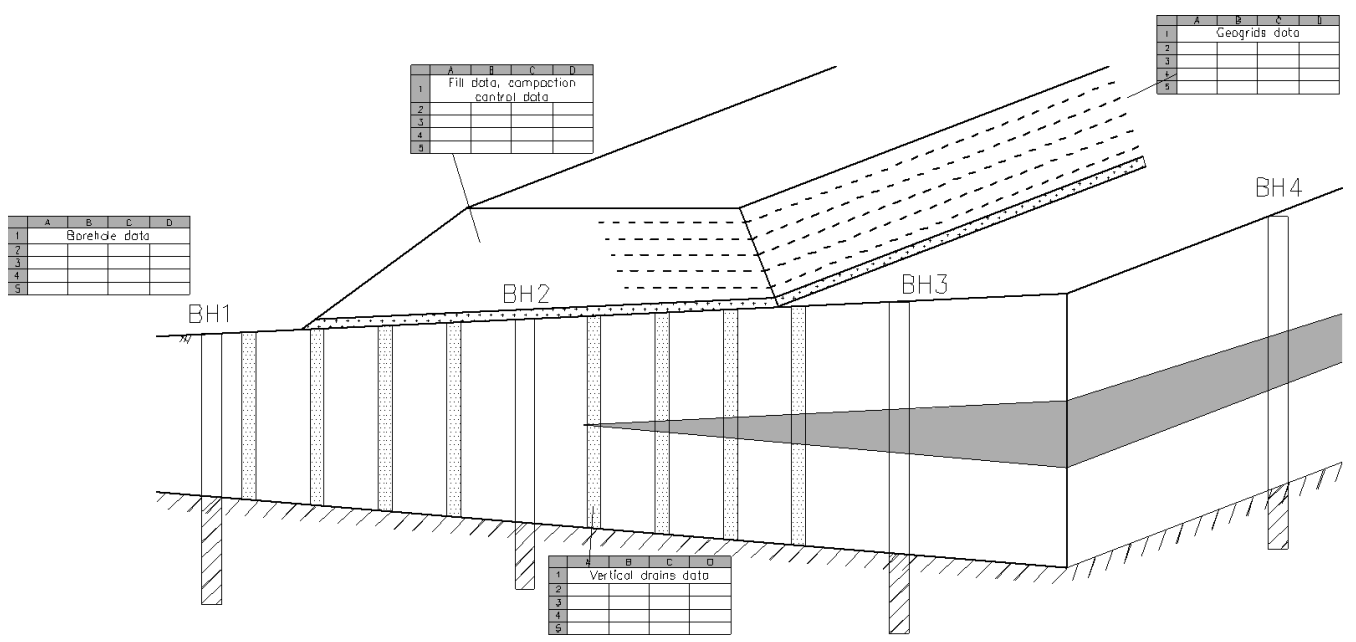

FIGURE 4. Vision of 3D model of earth structure within BIM

case the proposed BIM model is only approximated and any final modification according to the real geological and geotechnical conditions should be the result of the last phase of performance.

However, this last BIM version is very important for the phase of tunnel operation and maintenance - for Facility Management (FM). As in BIM, so also FM is a multi-criteria process. Sometimes FM is denoted in BIM as a sixth nongeometrical dimension - 6D BIM. The ITA - ITES (International Tunnel Association) devotes great attention to BIM at present. This is namely with respect to Tunnel Information Modelling (TIM) with the main aim to approve and support closer cooperation in the context of information management [6].

\section{Summary}

BIM is a long-term process which requires the preparedness of the people involved in, and familiar with, 
the new methods and processes which BIM is offering. With wider application of BIM in building and civil engineering new and more user-friendly software is appearing in this market. It is obvious that in the future transport infrastructures projects will almost certainly be realized involving BIM and information management. The rules for multi-disciplinary cooperation of individual subjects are already partly included in the standard of IFC. However, these standards are not applicable for some civil engineering structures such as tunnels. That is the reason why under the umbrella of ITA-ITES a new working group was established, namely for above mentioned TIM.

Nevertheless, in the field of geotechnical engineering BIM can bring many new positive features, predominantly from the viewpoint of limitation of the risk with which geotechnical structures are connected. Creation of the 3D model of subsoil together with the 3D model of geotechnical structures (either earth, foundation of underground) will help bring a better recognition of the geotechnical profession, especially its role in the whole process of construction. A great possibility exists with connection to the basic code for geotechnical structures - Eurocode 7 Geotechnical design. The creation of individual models is the common endeavour of EC 7. As for the standpoint of interconnection of individual phases and also for their control, that basic recommendation of the EC 7 appears satisfied.

A full exploration of BIM is duly justified given the basic aim defined for the BIM which is that it should be a reliable basis for the decisionmaking process during a full life time structure expectancy - from the early phase of conception up to the structure demolition. After that it would be easier to implement simply from principles of sustainable construction. However, it is very important to define the principles of sustainable construction from the earliest phase. For example, the effort directed towards lower land consumption (greenfield saving) should be defined at the beginning as it is connected also with transport line selection. Also, the possibility of land savings due to application of steeper slopes which are reinforced should start as soon as possible.

However, the principle of sustainability is connected also with savings of energy and natural materials as for example in the case of reinforced retaining structures - during the phase of final decision about their type - as this principle can play significant role, additionally with respect to the C02 path. Similarly it is valid for application of large volume waste materials into embankment such as flying ash, construction and demolition waste etc. instead of using natural soil.

The transfer of the currently used $2 \mathrm{D}$ subsoil model into $3 \mathrm{D}$ is not such a great model and the first signs of this are becoming recognisable. Similarly this is valid for design verification, with continuous transfer from $2 \mathrm{D}$ models into $3 \mathrm{D}$ models, even if the transport infrastructure where one dimensionality prevails, is more typical for $2 \mathrm{D}$.

Therefore, more positively discussed is the transfer of "our" now typical geotechnical models into the Coordination model of BIM for which the main coordinator is responsible. This transfer demands a good orientation to Code ČSN EN ISO 16739 Industry Foundation Classes (IFC) for data sharing in the construction and facility management industry (ISO 16739:2013), Especially, with respect to the fact that it is an open neutral standard data model, the transfer should not be a great problem - certainly after acquaintance develops confidence. The main coordinator will guarantee that this data model will be free of charge.

A final note merits focus on the utilization of BIM during life time expectancy. A basic model of subsoil together with a 3D model of geotechnical structure will be utilizable in the case of any new interaction. Interaction with a new construction affecting the old one or due to any natural hazards or indeed any manmade hazards such as different types of accidents, e.g. a lorry with chemical substance, can allow a quick reaction to protect subsoil contamination.

\section{ACKNOWLEDGEMENTS}

The paper was prepared with financial support from the programme of the Centre of Competence of the Technology Agency of the Czech Republic (TA ČR), No. of project TE0120168.

\section{REFERENCES}

[1] US National BIM Standard Project Committee. [online]. [28. 8. 2019]., Available at: https://www.nationalbimstandard.org/faqs\#faq1

[2] J. Nechyba (2018). Vládní koncepce BIM - rok po jejím schválení. Zprávy a informace ČKAIT, 5/2018.

[3] P. Kuba, D. Wallensfels (2019). Nová vodní linka ÚČOV: cesta od projektování $2 \mathrm{D}$ k projektování 3D a BIM. Stavitelství 04/19.

[4] J. Slánský, P. Bečička. (2019). Využití BIM na př́kladu projektu nemocnice Náchod. Stavitelství 09/19.

[5] M. Žibert. BIM IN TUNNELLING - Implementation of BIM methodology to Trans Alpine tunnel Karavanke. BrisBIM Gathering, August 2017, [online]. [28. 8. 2019]. Available at: http://brisbim.com/wp-content/uploads/2017/08/ 170822_iC_BIM-BrisBIM-KarTU_MZr.pdf

[6] Working Group 22: Information Modelling in Tunnelling. International Tunnelling and Underground Space Association [online]. [28. 8. 2019]. Available at: https://about.ita-aites.org/wg-committees/ working-groups/276-ita-active-working-groups/ working-group-22-new-2017-informationmodelling-in-tunnelling 